\title{
Relations between Industry and Academe in Scotland, and the Case of Dyeing: 1760 to 1840
}

\author{
Robert G.W. Anderson
}

What was the role of academic chemists in relation to those who were directly involved in developing Scotland's burgeoning chemical industry between 1760 and 1840 ? Traditionally, most historians have suggested that there was little involvement between academics and manufacturers across Europe. More recently, some historians suggest that it is difficult to disentangle their relations; it is best, they argue, to speak of hybrid identities. Neither extreme is sustainable when Scottish evidence is examined; an intermediate position, depending on the particular individual concerned, paints a more plausible picture. Some academics interacted closely with enterprising manufacturers, others less so. This essay provides a general introduction to the issues, followed by an analysis of the case of the pre-synthetic dyestuffs industry.

The traditional view holds that the academic world of the late eighteenth and early nineteenth centuries did not play a role. In a paper of 1797 , Theophilus Lewis Rupp (d.1805), a German-born Manchester cotton manufacturer wrote,

The arts, which supply the luxuries, conveniences, and necessaries of life, have derived but little advantage from philosophers [...] The chemist, in particular, if we except the pharmaceutical laboratory, has but little claim on the arts: on the contrary, he is indebted to them for the greatest discoveries and a prodigious number of facts, which form the basis of his science $[\ldots][\mathrm{N}]$ o brand of the useful arts is less indebted to him than that of changing the colours of substances. The art of dyeing has attained a high degree of perfection without the aid of the chemist, who is totally ignorant of the rationale of many of its processes, and the little he knows of this subject is of a late date. ${ }^{1}$

1 Theophilus Lewis Rupp, "On the Process of Bleaching with the Oxygenated Muriatic Acid; and a Description of a New Apparatus for Bleaching Cloths, with that Acid Dissolved in Water, without the Addition of Alkali," Memoirs of the Manchester Literary and Philosophical Society 5 (1798): 298-313.

(C) ROBERT G.W. ANDERSON, 2018 | DOI 10.1163/9789004325562_016

This is an open access chapter distributed under the terms of the CC-BY-NC License. 
This view was reiterated by the American economic historian Witt Bowden (1885-1979) in 1925 and by British economic historian, Peter Matthias (b.1928), who in 1983 wrote, "innovations were not the result of the formal application of applied science, nor a formal product of the educational system [...] determination, intense curiosity, quick wits, clever fingers, luck, capital [...] and a backer $[\ldots]$ were more important $[. .$.$] than a scientific training". { }^{2}$

A recent opposing view to this distinction between the academic world and industry has been developed by historian of science Ursula Klein, who asserts that throughout the eighteenth century,

[...] chemical science and technology were strongly and systematically linked with one another. The interconnection of chemical science and technology was not promoted by a few individuals occupied with both scientific and technological enterprises. Rather, this interaction was firmly established on the communal and institutional level of eighteenthcentury chemistry.

She stresses her point by applying the seemingly anachronistic concept of 'technoscience', the intricate entanglement of what have conventionally been considered as two different cultures, to cover both "savants experimenting at academic institutions and craftsmen and artisans producing in workshops." ${ }^{3}$ Practitioners, it is argued, essentially merged towards a single chemical culture. It must be asked, however, how generally applicable this was throughout Europe? Klein's evidence is largely taken from the German world (particularly that described in Karl Hufbauer's The Formation of the German Chemical

2 Peter Mathias, The First Industrial Nation: An economic history of Britain, 1700-1914, second edition (London: Methuen, 1983), 124-25; Witt Bowden, Industrial Society in England Towards the End of the Eighteenth Century (New York: Macmillan, 1925); second edition (London: Frank Cass \& Co., 1965), 11.

3 Ursula Klein, “Technoscience Avant la Lettre," Perspectives on Science 13 (2005): 226-66, quotations on 226-27; Klein goes so far as to use the term 'fusion' (226) to describe the degree of merging of the chemical cultures. On chemistry as a technoscience, see also Bernadette Bensaude-Vincent, “Chemistry as a Technoscience," Jean-Pierre Llored, ed., The Philosophy of Chemistry: Practices, methodologies, and concepts (Newcastle-upon-Tyne: Cambridge Scholars Publishing, 2013), 330-41; For an intermediate view, see Eda Kranakis, "Hybrid Careers and the Interaction of Science and Technology," Peter Kroes and Martijn Baker, eds., Technological Development and Science in the Industrial Age (Dordrecht: Kluwer Academic Publishers, 1992), 177-204, on 178 . 
Community). ${ }^{4}$ But if we attend to the relations in Scotland between university chemists and those who employed chemistry in the fields of manufacture and commerce over the period 1760 to 1840 , the more sophisticated and integrated German chemistry culture (particularly that in relation to pharmacy) cannot be assumed. ${ }^{5}$ Similarly, the German level of organisation in the field of mining, with its academies and ceremonial, did not exist in the same way in Scotland; neither did posts associated with them. Klein also describes the field of organic chemistry, in which new carbon compounds were produced, as technoscientific. But it was a particularly German and French development from the 1820s, whose activity led to an alliance between chemical science and the synthetic dye industry from the late 1850 .

Edinburgh, situated near the Forth valley where industrial initiatives were rapidly developing, was one of Europe's major centers of chemistry teaching in the later eighteenth century. To an extent the cultures of chemical pedagogy and industrial practices overlapped there. There was a significant amount of social interaction between many academic chemists and entrepreneurs and for some this extended further to levels of co-operation and advice. Their identities, however, generally remained connected either to academe or the industrial and commercial world. While academics were in touch with industry in a variety of ways, their main concern was clearly seen as transmitting chemical knowledge to future medical practitioners. ${ }^{6}$

Industrialists were certainly never involved in formal teaching activities and practically all chemistry teaching was conducted by those who had graduated with medical degrees. A few entrepreneurs had undertaken formal university education and some did subscribe to a course of chemistry lectures as nonmatriculated students. On occasion, academics were asked by industrialists, government agencies and publically funded bodies to offer advice on industrial and health matters. But, as said, they largely maintained their distinct identities.

4 Karl Hufbauer, The Formation of the German Chemical Community 1720-1795 (Berkeley: University of California Press, 1982).

5 Ursula Klein, "Apothecary Shops, Laboratories and Chemical Manufacture in Eighteenthcentury Germany," Lissa Roberts, Simon Schaffer and Peter Dear, eds., The Mindful Hand: Inquiry and invention from the late Renaissance to early industrialisation (Amsterdam: Royal Netherlands Academy of Arts and Sciences, 2007), 247-78.

6 The requirement for physicians to have knowledge of general chemistry has been little discussed by historians. The chemistry curricula taught includes a great deal of chemistry which had no bearing on their professional needs. Courses by chair holders in materia medica and botany which would have been much more relevant to the daily work of a general practitioner. 
From the foundation of the Edinburgh medical faculty in 1726 , it is possible to observe three phases in the relationship between the chemistry professors and industry up to the 1840 . During the first phase, the professor Andrew Plummer was directly involved with his medical colleagues in the production of drugs for distribution to pharmacies around Edinburgh, at least until 1742. They played a strongly entrepreneurial role: they were unsalaried and needed to earn more than their student fees brought in.

A second phase involving William Cullen and Joseph Black between 1747 and 1799, saw their close but distinctive relationship with industrialists, with whom their interests coincided. William Cullen (1710-90), lecturer in chemistry in Glasgow from 1747 and successor to Plummer in Edinburgh from 1756, was particularly damning of his teaching. He wrote in his notes, "Pharmaceutical Courses of Chemistry have not deserved the place they have hitherto held in our Schools - that they are not fitted to lead us to a general knowledge of Chemistry." ${ }^{7}$ Furthermore, he taught, "Some persons may expect very particular Inquiries on the Subject of certain Arts. Examples of the practice of these and Essays made for their Improvement and these arts they would chiefly attend to - but I here must inform such persons that we don't pretend to shew the practice of particular Arts in the way of Trade \& Business." ${ }^{8}$ The emphasis Cullen was making here was that he would not teach particular Arts - his teaching, while practical, would be generally applicable.

The third phase, involving Thomas Charles Hope, 1796 to 1843, saw much more polarization. Hope (1766-1844) was initially antagonistic even to the teaching of practical chemistry, though his attitude softened later in his career. In the world outside his lecture theater, major developments such as chlorine bleaching, were being pursued by industrialists (in Scotland, particularly by Charles Tennant (1768-1838) in Glasgow). Hope's only involvement with bleaching, however, seems to have entailed a single experiment, conducted in the presence of Humphry Davy (1778-1829) and other gentlemen, which concerned theory rather than practice. ${ }^{9}$ Hope's territory was based around the university's Old College and in the social round in Edinburgh's New Town, rather than sites of industry. His successor, William Gregory (1803-1858), did have some personal connection with the alkaloid industry in Edinburgh in that his method of mor-

7 R.G.W. Anderson, The Playfair Collection and the Teaching of Chemistry at the University of Edinburgh 1713-1858 (Edinburgh: Royal Scottish Museum, 1978), 11; Cullen probably attended Plummer's lectures as a student.

8 Ibid.

9 Archibald Clow and Nan L. Clow, The Chemical Revolution: A contribution to social technology (London: Batchworth Press, 1952), 500. 
phine production was taken up by the firm of J.F. Macfarlan in the 1830s, though this was more than a decade before he was selected for the Edinburgh chair. ${ }^{10}$ Two years before his appointment in 1844 , Gregory wrote a telling letter to the 4th Earl of Aberdeen (1784-186o), indicating a very different attitude from that of Hope:

If any nation is bound to encourage and promote the study of practical chemistry it is the British nation, which has derived, and continues to derive, such vast advantages from the applications of its principles to the useful arts. Yet, if we investigate the subject, we find that the opportunities afforded in this country for the study of practical chemistry are exceedingly limited.11

Glasgow offers other cases that are a bit more ambiguous. Andrew Ure (17781857) served as professor of natural philosophy at Glasgow's Anderson's Institution, lecturing also on chemistry and mechanics, from 1804 to 1830 , when he resigned his post to become what his biographer has called "the first consulting chemist in Britain." ${ }^{2}$ While his resignation emphasized a separation between the academic world and the realm of chemical industry, Ure had, for example, worked as a consultant to the Irish Linen Board in 1814. And, reflecting on his career in his highly successful Dictionary of Arts, Manufactures and Mines of 1839, which he described as embodying "the results of my long experience as a Professor of Practical Science," Ure spoke of his continued interest in educating his nation's practitioners. ${ }^{13}$

Those who studied in Thomas Thomson's laboratory in Glasgow University (where he was professor of chemistry from 1818 to $185^{2}$ ) also present us with a picture that neither conforms clearly to the traditional distinction between academic and industrial chemists nor the claim of chemists as hybrid 'technoscientists'. In his study of this cohort, Jack Morrell does divide them between the categories of "academic" and "industrial" chemists. But he is quick to add

10 Anderson, The Playfair Collection, p. 48 (see note 7).

11 William Gregory, Letter to the Right Honourable George, Earl of Aberdeen, K.T. [...] on the State of the Schools of Chemistry in the United Kingdom (London: Taylor \& Walton, 1842), 12.

Donald Cardwell, “Ure, Andrew," Oxford Dictionary of National Biography (Oxford: Oxford University Press, 2004).

Andrew Ure, Dictionary of Arts, Manufactures and Mines (London: Longman, Orme, Brown, Greene, \& Longmans, 1839), iv-v; For further consideration of Ure's career, see the discussion on his research on dyes below. 
that "the above classification is arbitrary" and specifically mentions Walter Crum, whose work in the field of dyeing is discussed below, as a "case in point". ${ }^{14}$

\section{Chemistry Teaching in Scotland}

Formal academic teaching of chemistry in Great Britain over the period 1760 to the late 1820 essentially entailed the courses available at Scottish universities, especially those of Glasgow and Edinburgh. The English universities, Oxford and Cambridge, did offer chemistry classes from time to time but the subject did not form part of the examined curriculum..$^{15}$ The University of London treated chemistry seriously from its beginning but that was not until after its foundation in 1826. The other two Scottish universities, St Andrews and Aberdeen, were small and did not particularly promote the subject of chemistry, though there was sporadic activity from certain professors. In contrast, Edinburgh and Glasgow were seriously involved with the subject. Edinburgh established a chair of chemistry and medicine in 1713 and its medical faculty thirteen years later. ${ }^{16}$ The University of Glasgow set up a lectureship from 1747 and appointed William Cullen. ${ }^{17}$ From these years onwards, a continuous series of appointments was made. In Glasgow, a Regius chair in chemistry was established in 1818. Both universities drew large classes. In the 1820s, Thomas Charles Hope's class at Edinburgh on occasion attracted more than 500 subscribers per annum. ${ }^{18}$

14 Jack Morrell, "The Research Breeders: the Research Schools of Liebig and Thomas Thomson," Ambix 19 (1972): 1-46, see particularly the lists on 21, 22; quotation on 21.

15 Mary D. Archer and Christopher D. Haley, eds., The 1702 Chair of Chemistry at Cambridge: Transformation and change (Cambridge: Cambridge University Press, 2005); Peter J.T. Morris, "The Eighteenth Century: Chemistry Allied to Anatomy," Robert Joseph Paton Williams, Allan Chapman and John Shipley Rowlinson, eds., Chemistry at Oxford: A history from 1600 to 2005 (London: Royal Society of Chemistry, 2008), 52-78.

John C. Powers, "Leiden Chemistry in Edinburgh: Herman Boerhaave, James Crawford and Andrew Plummer," Robert G.W. Anderson, ed., Cradle of Chemistry: The early years of chemistry at the University of Edinburgh (Edinburgh: John Donald, 2015), 25-58.

Andrew Kent, ed., An Eighteenth Century Lectureship in Chemistry: Essays and bicentenary addresses relating to the chemistry department of Glasgow University (Glasgow: Jackson Son \& Co, 1950).

For numbers of students registering for the annual course of chemistry lectures given by Thomas Charles Hope, see Jack Morrell, "Practical Chemistry in the University of Edinburgh, 1799-1843," Ambix 16 (1969): 66-8o (on 76, note 84). 
It is important not to ignore Anderson's Institution in Glasgow, established in 1796 (from 1828, renamed Anderson's University) through a legacy of John Anderson (1726-96), professor of natural philosophy at the University of Glasgow. ${ }^{19}$ Because the funds he bequeathed were insufficient to establish a fully-fledged university, it was decided to begin teaching natural philosophy and chemistry; other subjects were added subsequently. This was because the institution was established specially to teach manufacturers and artificers who had not previously undertaken mathematical studies. In some ways it can be seen as a precursor of mechanics' institutes. George Birkbeck (1776-1841), who is regarded as the prime originator of mechanics' institutes, taught at Anderson's Institution from 1799. It might thus be seen as ironic that it was this institution which Ure left to become an independent chemical consultant.

\section{Scotland's Universities and Industry}

Eighteenth-century Scottish chemists were encouraged to develop interests in industry by benefiting from premiums made available through a body which was established to promote the Scottish economy, the Board of Trustees for Fisheries and Manufactures in Scotland. This offered financial inducements, provided by the London-based British Government. ${ }^{20}$ From when it started in the 1720s, the initial sum set aside for this purpose was $£ 6000$ per annum. Among the higher priorities was encouragement of the linen industry, for which $£_{2} 65^{\circ}$ had been ring-fenced. The traditional means of whitening cloth - leaving it laid out on bleachfields for several days in the sun, sometimes adding sour milk - was clearly inefficient. Black and his colleagues suggested innovative bleaching techniques. Francis Home (1719-1813), professor of materia medica, was awarded a prize of $£ 100$ for his proposal to use dilute sulfuric acid in the process rather than sour milk. But it was not always to larger-scale industries that Black offered advice. In 1783 the Board asked him to adjudicate on Mrs Gordon's method of making wine vinegar. ${ }^{21}$

19 James Muir, John Anderson, Pioneer of Technical Education and the College he Founded (Glasgow: John Smith \& Son, 1950); John Butt, John Anderson's Legacy: The University of Strathclyde and its antecedents (East Linton: Tuckwell Press, 1996), 1-24.

Annette M. Smith, "State Aid to Industry - an Eighteenth Century Example," T.M. Devine, ed., Lairds and Improvement in the Scotland of the Enlightenment (Glasgow: 9th Scottish Historical Conference, 1978), 21-30. Joseph Black, 2 vols. (Farnham: Ashgate, 2012), vol. 1, 614-15; Mrs Gordon could not be identified. 
Andrew Ure reflected on this increasing input by academic chemists into manufacturing practices in the preface to his Dictionary of Arts, Manufactures and Mines.

I have embodied in this work the results of my long experience as a Professor of Practical Science. Since the year 1805, when I entered at an early age upon the arduous task of conducting the school of chemistry and manufactures in the Andersonian Institution, up to the present day, I have been assiduously engaged in the study and improvement of most of the chemical and many of the mechanical arts. Consulted professionally by proprietors of factories, workshops and mines, of various descriptions, both in this country and abroad, concerning derangement in their operations, or defects in their products, I have enjoyed peculiar opportunities of becoming familiar with their minutest details, and have frequently had the good fortune to rectify what was amiss, or to supply what was wanting. ${ }^{22}$

This judgment was by no means unique. In 1814, Sir John Sinclair (1754-1835), who promoted the compilation of the Statistical Account of Scotland, declared: "At present there are a greater number of intelligent practical chemists in Scotland, in proportion to the population, than perhaps in any other country of the world."23

Not much is known about laboratories situated in Scottish universities up to 1820 , and what went on in them. Occasional details are indicated when funds were applied for either from the University or (in Edinburgh's case) its patron, the Town Council. A certain amount can be deduced about extra-mural chemical laboratories, which were developed by freelance chemists to teach students who preferred to learn the subject outside the confines of a university. ${ }^{24}$ Other laboratories which were set up throughout Britain after 1821 included those attached to mechanics' institutes, bodies which initially were dedicated to providing education for the working class. The first one of these was the Edinburgh School of Arts. ${ }^{25}$ Its Glasgow counterpart, the Glasgow Mechanics' Institution,

\footnotetext{
22 Ure, Dictionary of Arts, p. iv (see note 13).

23 John Sinclair, General Report of the Agricultural State and Political Circumstances of Scotland (Edinburgh, 1814), appendix 2, 307.

24 Robert G.W. Anderson, "Chemistry Beyond the Academy: Diversity in Scotland in the early nineteenth century," Ambix 57 (2010): 84-103.

25 P.N. O'Farrell, Heriot Watt University. An illustrated history (Harlow: Pearson Educational, 2004).
} 
emerged two years later from a split in the mechanics class of Anderson's Institution. These various bodies were mainly concerned with teaching workers science. Much less is known about private laboratories (as opposed to teaching lecture theaters) used for experimental activity by the professors where personal investigation and research could be carried out. Black must have had private facilities for conducting his many analyses. ${ }^{26}$

Knowing about social relationships between academic chemists and entrepreneurs is useful to determine the role of each. Very little can be gleaned from published books and papers; more is available from correspondence. It is likely that much of the interaction was informal. The loosely structured Lunar Society in Birmingham was a locus for the exchange of ideas, but no formal minutes were kept which could provide evidence. ${ }^{27}$ In Edinburgh and Glasgow there were plenty of social clubs, but these, by their nature, left very little trace of what went on in them. Occasional light is shed in social letters. In one written in May 1784, John Hope (1725-86), professor of botany at Edinburgh, revealed to Matthew Boulton, "Last night we had a full meeting at the Oyster Cellar, Mr Cort, Lord Dundonald, Hutton, Black, MacGowan, etc. Dr Hutton whispered to me, what a number of projectors, and Black said I was a fool of a one myself. We had as usual a great deal of pleasantry, and every now and then some useful and interesting conversation." 28 This makes it clear that the Oyster Club brought together a group whose interests were complementary. The landowning aristocracy was represented by Lord Dundonald (1749-1831) whose estate at Culross was used for various industrial purposes; John McGowan (d.1803) was solicitor to the Customs and Excise; Henry Cort (1741-1800) was an innovative ironmaster; and James Hutton (1726-1797) could be described as an Edinburgh chemical manufacturer (that was where his income was made; he held no post in geology). ${ }^{29}$ These men were carousing on equal terms with the university professoriate represented by Joseph Black and John Hope (1725-86), whilst having "every now and then some useful and interesting conversation."

This indicates the importance of letters as evidence. Black's correspondence of about 830 items is the key to revealing his relationship with entrepreneurs

26 Black certainly had a private room: Adam Ferguson made a comment about its tidiness, it "never being lumbered with [...] the apparatus of experiments", see Anderson and Jones, Correspondence, vol. 1, p. 49 (see note 21).

27 What evidence there is has been assembled by Peter M. Jones, see his Industrial Enlightenment: Science, technology and culture in Birmingham and the West Midlands (Manchester: Manchester University Press, 2009), 82-94, especially Table 3.0 on 92-3.

28 Clow and Clow, The Chemical Revolution, p. 415 (see note 9).

29 On Hutton, see the essay by Lissa Roberts and Joppe van Driel in this volume. 
and industrialists. ${ }^{30}$ Nearly seventy of his correspondents sought direct advice on industrial issues. Through this evidence, there can be no doubt that Black contributed a great deal to the developing chemical industry in Scotland and elsewhere. It is possible to categorize his assistance under five heads. He corresponded with landowners who wanted to improve agricultural yields. For this cohort he also conducted mineral analyses in his laboratory to determine how to extract metals profitably. He was frequently contacted by the Board of Fisheries and Manufactures to help them make judgments on giving grants and premiums to those submitting new ideas for improving various processes. The Board of Customs asked him about issues concerning taxation. Finally, he was contacted by those seeking advice on the likely commercial viability of developing new chemical works.

Throughout all this, it is not clear what Black himself gained. Was he was simply being philanthropically responsive? One scheme certainly did occupy his time, thought and energy. This was his own attempt to produce alkali by a cheap method. Soda and potash were important in the Scottish industry, not only textiles but glass and soap as well. Traditional methods of alkali production, by burning wood or seaweed and leaching-out salts, were extremely inefficient, though Black advised on this, determining experimentally which ferns from various Scottish estates offered the best yield. ${ }^{31}$ Statistics were also determined for kelp found on various Scottish beaches. ${ }^{32}$ It was important because imports from overseas, especially Spanish barilla, were subject to interruption by the many wars and skirmishes of the period. There would be significant financial rewards if a new chemical process using cheap reagents could be made to work. The attempted method was to juxtapose plates of solid salt and lime, hoping to get them to react together by means of a double decomposition which, it was hoped, would result in soda and chloride of calcium. Experiments by Black were conducted in parallel with James Watt's in Glasgow and their correspondence reveals their frustration at their failure, even though over-optimistically, at the same time, they talked about patenting the process. Watt's work was on a large scale; he refers to a reagent 'house' being constructed, 36 feet in length, 18 feet wide and 15 feet in height; he estimated that after one year, nine tons of alkali would be produced. Black at a

$30 \quad$ Anderson and Jones, Correspondence, 2 vols. passim (see note 21).

$31 \quad$ Ibid., pp. 511-13, letter from Black to Ebenezer Macculloch, 9 July 1782; Mcculloch is described here as 'General Surveyor of the Linen Manufactures, under the Honble. Board of Trustees'. Kelp and Barilla," Transactions of the Highland Society 5 (1820): 10-64, on 29. 
later stage spoke in general about how long his experiments took to conduct (though he did not specify which experiments these were). ${ }^{33}$ Both men were certainly concerned that others would develop a viable scheme before they did. ${ }^{34}$ This hands-on experimentation with an industrial process in mind was exceptional. It seems unlikely that Black's laboratory facilities resembled Klein's description: "large parts of the academic chemical laboratory instruments resembled the instruments of assayers, smelters, apothecaries, and distillers"; there was simply insufficient space. ${ }^{35}$

More details are known about experiments requested by others because some replies survive. Black had a particularly extensive correspondence with Henry Home, Lord Kames (1696-1782), a scientifically minded judge, agricultural improver and leading member of the Edinburgh literati. ${ }^{36}$ Kames was attempting to drain part of his estate and turned to Black because he wanted to know about the nature of alluvial clays. He wrote in a preface to one of his books, "An imprimatur from one of the ablest chymists of the present age [that is, Black] has given me some confidence of being on the right track." ${ }^{37}$

The Board of Fisheries and Manufactures generally turned to the academic world for advice on practical matters. An example involving Black (and James Hutton) concerned the development of a new type of furnace designed by one William Cottrell (fl.1780s), intended for the smelting of ores to produce pig iron. ${ }^{38}$ Black and Hutton had their doubts from the outset, but "Since so much has already been laid out upon an experiment, which seems to be conducted with ingenuity, we should be sorry not to see it brought to some conclusion."39 A very thorough report was finally submitted on 27 October $1783 .{ }^{40}$

\footnotetext{
33 Anderson and Jones, Correspondence, vol. 2, pp. 1068-69 (see note 21).

34 See correspondence between Black and Watt, 23 January to 10 July 1769 in ibid., vol. 1, especially pp. 206-13.

35 Klein, “Technoscience," p. 240 (see note 3 ).

36 Anderson and Jones, Correspondence, vol. 1, pp. 312-322 and 323-329 (see note 21).

37 Henry Home, The Gentleman Farmer; Being an attempt to improve Agriculture by subjecting it to the test of rational principles (Edinburgh: W. Creech, 1776), xii-xiii.

$3^{8}$ Anderson and Jones, Correspondence, vol. 1, pp. 649-50 (see note 21). Letter from Robert Arbuthnot, Secretary to the Board, to Black and Hutton, 27 June 1783 .

39 Ibid., vol. 1. pp. 650-52. Draft letters from Black and Hutton to the Board of Fisheries and Manufactures, after 27 June 1783 .

40 Ibid., vol. 1, pp. 670-75. Report of Black and Hutton submitted to the Board of Fisheries and Manufactures, 27 October 1783 .
} 
The Board of Customs consulted Black about the point at which poor quality, untaxed 'culm' becomes taxable, good quality coal. ${ }^{41}$ Another commission for Customs and Excise carried out by Black related to whether tax should be exacted on the other salts in sea water, as it was on common salt and focused on the substance bittern (the solution remaining when seawater has been concentrated by evaporation, to the point where the common salt component has crystallized out). ${ }^{42}$ The Collector of Customs at Port Glasgow wanted to know, for a start, what it was. Although Black was willing to give advice on scientific aspects of the matter and carry out calculations, he made it clear that he did not want to be drawn into giving an opinion which would affect tax legislation. ${ }^{43}$

Black was astute when it came to judging financial consequences of establishing industrial processes, something which perhaps would not be expected of an eighteenth century academic scientist. This comes through very clearly from Black's correspondence with Archibald Cochrane, gth Earl of Dundonald. Cochrane owned an estate on the north shore of the Firth of Forth at Culross. Not a wealthy man, he developed various industrial schemes which, he hoped, would ease his financial situation. Black was cautious about Cochrane's ability to bring anything he started to a successful conclusion. He wrote to Cochrane's brother-in-law in surprizingly forthright terms:

In my preceeding conversations with his Lordship he had appeared to me to be very ingenious \& acute but at the same time so overflowing with Projects \& so extreamly [sic] sanguine [...] I may say extravagant in his estimation of them that I neither expected to find any thing Solid or Satisfactory nor had the least hope that my advice or opinion would be attended to. ${ }^{44}$

One of these Projects was tar production, which Cochrane intended to produce by distilling coal, available on his estate. Cochrane had ambitions to sell

41 Ibid., vol. 1, pp. 345-38; On culm, see also the essay by Roberts and Van Driel in this volume.

42 Ibid., vol. 2, pp. 1214-15 and 1216-23.

43 William Ramsay, Life and Letters of Joseph Black (London: Constable, 1918), 108; The letter from which Ramsay made this judgment no longer survives. Contrast this with the role of academic chemists as advisors to the Dutch government, see Joppe van Driel and Lissa Roberts, "Circulating Salts: Chemical governance and the bifurcation of "nature" and "society", Eighteenth Century Studies 49 (2016): 233-63.

44 Anderson and Jones, Correspondence, vol. 2, pp. 599-602 (see note 21). Letter, Black to Andrew Stuart, Edinburgh, 25 January 1783. 
his tar to the Navy to preserve ships' bottoms from becoming worm-eaten. Black's analysis was very detailed, considered under six separate headings. He performed different sets of calculations showing that the income at time of war would be greater than if the country were at peace (the weekly value would be £88.8.o compared with £69.16.o, respectively). ${ }^{45}$ Of Black's highly practical contribution to Cochrane's enterprise, Sir John Dalrymple, Solicitor General for Scotland, wrote that Black was, "the best judge, perhaps in Europe, of the merit of such inventions." 46

Though it is clear that Black was a key figure in advising on the development of a variety of industrial ventures, he was cautious about getting too involved - and he was good at making excuses, even to the aristocracy. When the Earl of Hopetoun, who had asked Black to analyze samples of gravel for gold, summoned him to Hopetoun House in March 1772, a distance of less than 13 miles, Black wrote, "I intended to have taken the opportunity of the present holidays to have paid my respects to your $\mathrm{L}^{\mathrm{d}}$ ship at $\mathrm{H}^{\mathrm{p}}$. House but the change of the weather made me delay that Ride to another time." ${ }^{47}$ There are other similar examples of this attitude.

Thomas Charles Hope did not play the same sort of role as Black in advising those developing industries, though much less is known about his personal inclinations; very little of his correspondence survives. Hope himself declared, "I consider my vocation to be the teaching the science [chemistry]."48 Until recently, it was thought that Hope cared little about developing up-to-date content for his chemistry course, but reference to his teaching notes show that he was well aware of innovations and he updated his teaching continually. ${ }^{49}$ Though it is fair to say that he concentrated largely on more theoretical aspects, he did not ignore the industrial side of chemistry as seen in relation to dyes.

George Wilson (1818-59) was an Edinburgh figure who operated at the borders of university teaching and was significantly involved with industrialists. ${ }^{50}$

45 Ibid., vol. 1, pp. 580-89. Black's notes and calculations.

46 John Dalrymple, Addresses and Proposals [...] on the Subject of Coal, Tar and Iron Branches of Trade (Edinburgh: Thomson Gale, 1784).

47 Anderson and Jones, Correspondence, vol. 1, pp. 250-52. Letter, Joseph Black to the 2nd Earl of Hopetoun, 14 March 1772.

48 Thomas Stewart Traill, "Memoir of Dr Thomas Charles Hope," Transactions of the Royal Society of Edinburgh 16 (1849): 419-34, on 431.

49 Robert G.W. Anderson, "Thomas Charles Hope and the Limiting Legacy of Joseph Black," Anderson, ed. Cradle of Chemistry, pp. 147-62 (see note 16).

$5^{0}$ Jessie Aitken Wilson, Memoirs of George Wilson (Edinburgh: Edmonston and Douglas, 1860). 
Trained in medicine at Edinburgh, Wilson had no intention of practising, seeing his training as preparing him for a career in chemistry. After graduation in 1838 he turned down an offer to work with Thomas Graham at University College, London, settling into a life of teaching chemistry extramurally in Edinburgh. In 1855, when a search was on for someone to direct the newly established Industrial Museum of Scotland, one of Wilson's former university colleagues, the influential Lyon Playfair (1818-98), recommended him for the job. Though it would be several years before a museum building became available, Wilson was immediately active in summoning the help of industrialists to fill his stores with teaching material. ${ }^{51}$ The University became concerned that Wilson, a popular teacher, would usurp the role of professor of chemistry, so it created a Regius Professorship of Technology and appointed Wilson to it. It could thereby exert a degree of control over his activities. Wilson's policy for teaching industrial processes was clearly set out in two lectures given at the Philosophical Institution in $1856 . .^{52}$ At least forty-eight extramural chemistry lecturers who taught courses starting between 1768 and 1855 were involved in a similar way. ${ }^{53} \mathrm{~A}$ small proportion of these were involved in industrialization. George Dixon Longstaff (1799-1892), for example, conducted tar distillation at Leith shortly after graduating and then returned to England where he developed industrial interests in oils, colors and varnish while teaching at mechanics institutions. ${ }^{54}$

\section{The Case of Dyes}

The considerable importance of the linen and cotton industry in Scotland provides context for Joseph Black's keen interest in dyeing. ${ }^{55}$ He prepared Prussian Blue in front of his class, a fact recorded by Thomas Charles Hope in his student

$51 \quad$ R.G.W. Anderson, "What is Technology?': Education Through museums in the mid-nineteenth century," British Journal for the History of Science 25 (1992): 169-84.

52 George Wilson, On the Objects of Technology and Industrial Museums. Two lectures addressed to the Philosophical Institution, Edinburgh, in February 1856 (Edinburgh: Sutherland \& Knox, 1856).

53 Robert G.W. Anderson, "Chemistry Beyond the Academy: Diversity in Scotland in the early nineteenth century," Ambix 57 (2010): 84-103.

54 Anon., "George Dixon Wagstaff," Journal of the Chemical Society 63 (1893): 751-54.

55 Alastair J. Durie, The Scottish Linen Industry in the Eighteenth Century (Edinburgh: John Donald, 1979), 32-94. 
lecture notes as having taken place in March $1784 .{ }^{56}$ Some of Black's correspondence is directly concerned with dyestuffs, especially the dyes cudbear and Turkey red. ${ }^{57}$ George Mackintosh (1739-1807), partner in a Glasgow concern which manufactured these dyestuffs wrote to Black: "I have late discovered a preparation which makes cudbear dye linen and cotton with the same ease, as it does woollens, which till now it could not do. I would cheerfully lay my process before you could I expect to be honoured with your sentiments upon it, as I want to have it fully complete before I discover it to the public." ${ }^{n 8}$ Obvious from this is that Mackintosh was seeking Black's valued imprimatur.

In November 1782, Mackintosh wrote again to thank Black and ask for his "approbation and opinion [of] the late discovery I made of making cudbear strick [sic] on linens and cottons." ${ }^{\prime 59}$ Later in November 1782 , he sent six samples of dyed linen and five samples of dyed silk thread to Black. Perhaps Mackintosh felt that he was writing too often, "[b]ut it is an affair of some importance to individuals." ${ }^{\prime 60}$ Black's replied encouragingly, ending his letter with a friendly promise to keep details of their correspondence secret, ${ }^{61}$

The final letter of the sequence is from Mackintosh to Black in 1785, when he sent Black six handkerchiefs "of a very excellent colour." The letter refers to a French dyer, probably Pierre Jacques Papillon (fl.1780s-90s), who came to work in the extensive dyeworks at Dalmarnock established by Mackintosh and David Dale. He was one of a succession of European dyers who struggled to learn the secret of making fast red dye from madder. Papillon arrived in Glasgow in 1785, via Manchester. The dye he produced was considered to be excellent, though he was an employee rather than a partner and he left in 1787 . He petitioned the Board of Manufactures on three occasions, between 1787 and 1790 , for a grant to set up and run his own dyeworks, to which they were sympathetic, but quickly realized that they could scarcely offer him money

56 Thomas Charles Hope's lecture notes taken in Black's class, 1783-84, Edinburgh University Library Research Collections, Ms Dc.10.95. Hope dated the demonstration as being done in March 1784 .

Turkey red was used widely in Scottish works, developed in 1785 at Dalmarnock on the River Clyde near Glasgow. The excellent color was obtained from the rubia plant by a complicated process. See W.T. Johnston, The Secret of Turkey Red (Livingston: Officina W.T. Johnston, 1993); see also Clow and Clow, Chemical Revolution, pp. 217-19 (see note 9).

$5^{8}$ Anderson and Jones, Correspondence, vol. 1, pp. 522-24 (see note 21). Letter, Mackintosh to Black, 31 August 1782.

59 Ibid., vol. 1, pp. 543-45. Letter, Mackintosh to Black, 2 November 1782.

6 Ibid., vol. 1, pp. 545-57. Letter, Mackintosh to Black, 4 November 1782.

61 Ibid., vol. 1, pp. 550-1. Draft letter, Black to Mackintosh, n.d. 
from public funds for a secret process. ${ }^{62} \mathrm{~A}$ solution was eventually found: Black was asked to examine Papillon's petition, in confidence, and adjudicate it. This he did, with a positive recommendation. It was agreed that there would be a ban on publication of the process for a period of twelve years, after which it would be made publicly available. ${ }^{63}$

Another interaction Black had concerning dyes was with William Hamilton (1758-1807) in 1791. Hamilton was an Irishman who had been a student of Black's when working for his MD, awarded in 1779. Hamilton had been translating Éléments de l'Art de la Teinture by Claude Louis Berthollet (1748-1822), published in Paris in 1791. He complained to Black that someone else was publishing another translation of the same book, implying piracy, and that Black had sanctioned it. ${ }^{64}$ Black explained in a reply that he had asked for a copy of the original French version, and having received a copy, he was asked by a publishing firm whether it should be translated. ${ }^{65}$ Black commended it highly, saying that it would be very useful and should be published in English. Sample pages of translation received a favorable opinion from him and the book was duly produced - which was what so distressed Hamilton. Again, this incident indicates the status which Black had achieved in being sought to make judgments on industrial matters.

In 1795, Black purchased a bond for $£_{500}$ sterling from Robert Graham of Gartmore (1735-1797) in the Culcreach (or Culcruech) Cotton Company, a very substantial sum. ${ }^{66}$ Black's relationship with Graham, who was a considerable landowner, politician and poet, is not known; no correspondence between them survives. Graham was Rector of Glasgow University between 1785 and 1787, which possibly explains how they knew each other. The Culcreach Company had been established at Fintry, in the Campsie Hills, twenty miles north of Glasgow, by Alexander Spiers. ${ }^{67}$ Black also took out a $£ 500$ sterling bond with the Edinburgh and Leith Glasshouse Company. He had developed a close friendship with its proprietor, Archibald Geddes, but the professional

\footnotetext{
62 Johnston, Secret, appendix 2, pp. 11-14 (see note 57).

63 Papillon's Turkey red process was published in the Edinburgh Evening Courant on 1 December 1803 .

64 Anderson and Jones, Correspondence, vol. 2, p. 1151 (see note 21). Letter, Hamilton to Black, 14 January 1792.

65 Ibid., vol. 2, p. 1152. Draft letter, Black to Hamilton, n.d.

66 Ibid., vol. 2, p. 1467: "Minutes taken at the opening of the Repositories of the late Dr. Joseph Black [...] Bond by Robert Grahame of Gartmore esq \& other partners of the Culcreuch Company for $£_{500}$ St in favor of the said Dr Black - dated 2d. Decr. \& 8 Dec. 1795."

67 Some papers are in Glasgow University Library Special Collections, Ms Gen 1717.
} 
roles of the two men appear distinct; Geddes attended two sessions of Black's chemistry class, paying his three guineas per session, like everybody else.

Hope's sparse research interests were different from Black's: he was the son of John Hope, holder of the chair of botany at Edinburgh, and a few of his published papers dealt with plant chemistry. There was quite a substantial section on inks and dyeing in his chemistry course, the evidence for this being found in the notes from which he lectured. He started the latter subject of his course by stating: "The Art of Dyeing is one of the most interesting of the Chemical Arts - It comprehends the methods of applying \& fixing durably colouring matter on animal \& vegetable fibre, so as to communicate on the endless variety of beautiful Tints [...]. Every process is in fact chemical one \& often very intricate." He then offered definitional discussions of dyeing in general and topical dyeing, further explaining that:

If no Chemical Attraction be exerted between the fibre of the stuff \& the colouring matter, this matter having been soluble \& actually dessolved in the water of the vat, continues soluble in the same menstruum - consequently when the dyed stuff is treated with water the colouring matter is compleatly carried off \& the stuff again becomes colourless. ${ }^{68}$

Following this introduction to the subject, Hope continued with a section on fixing coloring agents with mordants - solutions of alum or tin salts. He then treated indigo: "Dr Roxburgh of Calcutta teaches [...] leaves of Nerium Tinctorum, or diffr. Species of Indigofera are mixed with cold water in a boiler wc. Is heated slowly to $150^{\circ}$ \& then the clear water is strained off - Dr Roxburgh has proved that the production of the Blue substce or Indigo is owing to the absorption of Oxyg by the Green base." 69 In 1809, Hope felt that, as usual, he was running behind with his course and he decided not to discuss lichens and cudbear. ${ }^{70} \mathrm{He}$ did go on to teach a substantial section on how patterns are printed on to calico.

68 Edinburgh University Library Research Collections, Ms Gen 268-277, envelope 9, 'Astringents/Colouring Matter'.

69 William Roxburgh (1751-1851), a Scots surgeon working in Calcutta, had been taught by Thomas Charles Hope's father, John Hope; he experimented with sources of indigo for dyes from 1790, see Alexander Dalrymple, Oriental Repertory, 2 vols. (London: G. Biggs, 1793-1797), vol. 2 (London, 1793), 39-44; Roxburgh's full paper was published 18 years later: William Roxburgh, "Account of a new Species of Nerium," Transactions of the Society [...] for the Encouragement of Arts 28 (1811): 251-307.

70 Cudbear is a natural red-purple dye, extracted from lichens. Its production was patented in 1758 by George and Cuthbert Gordon, and from 1764 it was manufactured in Leith, 
Glasgow academics, including Andrew Ure when he was professor of natural philosophy at the Andersonian Institution, were also interested in dyes from a chemical point of view. Relevant to the Scottish dye industry is Ure's 1824 translation of Berthollet's Elements de l'Art de Teinture. Acknowledging that it had previously been translated and published by Hamilton, Ure's excuse for another edition was that Berthollet had added to his original work. ${ }^{71}$ There must be doubts about this claim. Berthollet's second edition appeared in 1804, Ure's translation was published in 1824 . It seems very likely that the translation was a vehicle for publishing the considerable research into dyes which Ure was carrying out. There are, in fact, 138 pages of notes which are pure Ure. Passages from Elements of the Art of Dyeing indicate that he considered that laboratory experiments were necessary if dyeing were to improve; the manufacturing arts would only improve if they were guided by science. In the Introduction to his 1824 book, he wrote:

The Arts can make but limited progress, when they are directed merely by a blind practice. Thus, they have remained for several centuries in nearly the same state in China and in India. But if artisans be guided by the knowledge of those properties which have been investigated by physics, and its complement, chemistry, there is no boundary to the perfection which they may reach. How many advantages has that nation, so powerful by its industry, derived from Watt, Wedgwood, Henry, and some other philosophers. In this respect a happy revolution has been affected among ourselves. Our manufacturers are no longer intrusted to ignorant workmen. In the greater part of them are found to be enlightened individuals, well informed philosophers, to whom indeed we must have recourse, if we wish to excite the progress of the useful arts, and remove the obstacles which stand in their way. ${ }^{72}$

It becomes apparent from Ure's remarks at the end of volume two, that he was conducting his own experiments on dyes, not just translating Berthollet's text. For example, when considering the relation between chemical change and color in indigo, he wrote:

though not very successfully. See Cuthbert Gordon, Memorial of Mr. Cuthbert Gordon, Relative to the Discovery and Use of Cudbear, and Other Dying Wares (London: s.n., 1784). C.L. and A.B. Berthollet, Elements of the Art of Dyeing [...] Translated from the French [...] With Notes [...] by Andrew Ure, 2 vols. (London: Thomas Tegg, 1824), vol. 2, xxiv. Ibid., vol. 2, p. 1. 
While engaged in these experiments, I discovered that if the action of sulphuric acid upon indigo be stopped at a certain point, a new substance, altogether different from cerulin, is produced, formed at the instant that indigo changes from yellow to blue by the action of sulphuric acid. $^{73}$

Concerning alternative chemical substances to alum as mordants, he indicated clearly that he had been conducting tests of his own: "Although all researches hitherto made have been ineffected [sic] to find a substitute for alum, we have nevertheless made trial of a great number of substances with wool." ${ }^{74}$ The ongoing nature of his experimental work to create a particular color is clearly understood by this statement: "We propose to determine the chemical nature of the combination formed upon wool by cochineal, tartar, and a solution of tin, and to make known the result of our enquiries upon the colour of scarlet."75 As if to emphasise his hands-on activity, the 1841 edition of Elements of the Art of Dyeing, published seventeen years later, has as its subtitle: A New Edition, Revised and Corrected by an Experienced Practical Dyer and Calico Printer.

A number of others were making knowledgeable contributions to dyeing in or near Glasgow, one being Walter Crum (1796-1867), who bridged the academic and industrial worlds. ${ }^{76} \mathrm{He}$ attended Glasgow University, studying under Thomas Thomson. His university career culminated in a paper published in Annals of Philosophy of 1823 on the subject "Indigo". ${ }^{77}$ This contains a good deal of detail about his laboratory experiments and refined analytical technique. Thereafter he joined his family calico printing business at Thornliebank, now

\footnotetext{
73 Ibid., vol. 2, p. 372 .

74 Ibid., vol. 2, p. 324.

75 Ibid., vol. 2, p. 326.

76 Anon., "Obituary Notices of Fellows Deceased," Proceedings of the Royal Society of London 16 (1868): viii-x ("The intimate knowledge that Mr Crum thus acquired combined with his general scientific attainments, enabled him to introduce many useful improvements into his own business and increase the excellence of its manufactures."). For details of Crum's interest in the theory of dyeing, see Bernadette Bensaude-Vincent and Agustí NietoGalan, "Theories of Dyeing: A view on the long-standing controversy through the works of Jean-Francois Persoz," Natural Dyestuffs and Industrial Chemistry in England, 1750-1880, eds. Robert Fox and Agustí Nieto-Galan (Canton: Science History Publications, 1999), 3-24.

77 Walter Crum, "Experiments and Observations on Indigo, and on certain Substances which are produced from it by means of Sulphuric Acid," Annals of Philosophy (February 1823): 81-100.
} 
a Glasgow suburb. But he continued to have scholarly urges and he published various papers pertinent to dyeing, Between 1830 and 1861 he regularly offered papers to the Philosophical Society of Glasgow. In 1844 he was appointed a Fellow of the Royal Society of London. In that same year, he proposed a theoretical interpretation of the interaction between cotton fibers and natural dyes, which brought him into contention with the French color chemist, JeanFrançois Persoz (1805-68), who held an alternative theory. ${ }^{78}$ Though primarily a manufacturer, Crum maintained scientific contact with Thomas Thomson, Michael Faraday, Jean-Baptiste Dumas, Alexander von Humboldt and Justus von Liebig. As mentioned above, it is indeed difficult to categorize his position, whether as an academic or an industrialist.

\section{Conclusion}

There are large gaps in our knowledge of the contribution made by academic chemists to the Scottish industrial world, in the case here, of dyeing in Scotland in the pre-synthetic dyestuffs era. It is indisputable, however, that academe made a distinctive contribution. In this particular case, and probably others as well, it is not unreasonable to challenge the theses of Rupp, Bowden and Matthias, but equally to question the extent to which Klein's 'technoscience' label is applicable, in determining the degree of separation or interlacing of the roles of academic chemist and industrial practitioner. Joseph Black, in one of his lectures, made a most telling statement about his personal attitude to their relationships, which veers the argument somewhat more towards Klein's view than that of Matthias et al.

I call every man a Philosopher who invents anything new or improves any business in which he is employed - even the Farmer who considers the nature of different soils or makes improvements on the ploughs he uses, I must call a Philosopher, though perhaps you can call him a Rustic one. Nor am I inclined to give much credit to those men who shut up their Closets in study and retirement have obtained the appellation of Learned Philosophers they in general puzzle more than they illustrate, they are

78 Walter Crum, "On the Manner In which Cotton Unites with Colouring Matter," Philosophical Magazine 24 (1844): 241-46; Bensaude-Vincent and Nieto-Galan, "Theories," pp. 8-14 (see note 76 ). 
wrapt in a veil of Systems and of Theories and seldom make improvements or discoveries of Use to Mankind. ${ }^{79}$

79 Quoted in Margaret C. Jacob and Larry Stewart, Practical Matter: Newton's science in the service of industry and empire (Cambridge, MA: Harvard University Press, 2004), 116-7; This quotation comes from lecture notes taken by Lowell Edgworth, who probably attended the 1795-96 final course given by Black, with Hope's assistance. 